\title{
Pensamento crítico, formação de psicólogo e atuação junto à infância e juventude
}

\author{
Maria Fatima Pereira Alberto \\ Universidade Federal da Paraíba
}

\begin{abstract}
Resumo
O objetivo é relatar a experiência de construção de um pensamento crítico na formação de psicólogos para atuação na área da infância e juventude. Usa-se a Psicologia Sócio-histórica que concebe o ser humano como ativo, social e histórico, constituído e constituinte das práticas sociais. Aliam-se formação e intervenção. A formação se dá em via de mão dupla, a produção de conhecimento gera intervenção e a intervenção gera produção de conhecimento que se processa através da intervenção em contextos de riscos para a infância e juventude. A atuação se dá no sentido de promover a articulação do objetivo e subjetivo, individual e social, contribuindo na transformação da realidade.
\end{abstract}

Palavras-chave: pensamento crítico; formação de psicólogo; atuação profissional; infância e juventude; riscos.

\begin{abstract}
Critical thinking, training of psychologist and practice to childhood and youth. The objective is to report the experience of creating critical thinking in the training of psychologists to work in the field of childhood and youth. Sociohistorical Psychology that comprehends man as active, social and historical, constituted and constituent of social practices is used. Training and intervention are joined. Training happens in two-ways, knowledge production creates intervention and intervention creates knowledge production and it is processed by intervention in contexts of risk for childhood and youth. Practice happens in a way that promotes the linkage between subjective and objective, individual and social, and helps to transform reality.

Keywords: critical thinking; psychologist training; professional practice; childhood and youth; risks.
\end{abstract}

$\mathrm{O}$ objetivo deste artigo é relatar uma experiência de construção de um pensamento crítico na formação de profissionais de Psicologia para atuarem na área da infância e juventude em situação de risco. Essa experiência tem se efetivado num contexto histórico específico, da criança e do adolescente, como sujeitos de direitos e que tem se dado em instituições que atuam na garantia desses direitos, numa perspectiva crítica, de modo a articular teoria e prática, graduação e pós-graduação, ensino, pesquisa e extensão, visando também a transformação dessa realidade social.

$\mathrm{Na}$ história da Psicologia, os caminhos tomados pela formação se deram por uma opção pela cientificidade e pelo rechaço às questões sociopolíticas. Tal formação desenvolveuse num contexto histórico e científico em que se priorizaram formas de intervenções voltadas para segmentos sociais mais abastados (Bock, Furtado \& Teixeira, 2001), numa identidade profissional marcada pelo modelo autônomo e pela produção de conhecimento sob "influência do positivismo, pautada no modelo médico, valorizada pelo uso de instrumentais de diagnóstico, com base em um conceito de normalidade" (Conselho Federal de Psicologia [CFP], 2009, p. 29) vigente na época.

No âmbito da Psicologia do Desenvolvimento, a emergência das práticas voltadas para a infância e juventude vigorou essencialmente a partir de dois modelos: clínico, construído sob a influência da origem das diferenças, voltado para cura e tratamento; e o escolar, separando-se os aptos dos não aptos para a aprendizagem, caracterizando-se, assim, um pensamento excludente, linear, ou seja, de causa e efeito. Ambos baseavamse no contexto científico vigente na época, o da Biologia Evolucionista, fundamentada nas características internas, na visão inatista. Dessa, emergiram práticas psicológicas destinadas ao controle dos sujeitos por meio da disciplina ou valorização de um suposto indivíduo autônomo, que, por sua vez, remetia a uma ordem natural. Por outro lado, uma prática que também se desenvolveu foi a da psiquiatrização da infância, modelo de atendimento cujas práticas combinavam instituições de saúde e de aprendizagem (Lobo, 2003).

São exemplos desse contexto a criação, no Rio de Janeiro, de algumas instituições que se definiam como de proteção, mas cujas práticas se voltavam para o controle: a) 1901: Instituto de Proteção da Infância (Moncorvo Filho); b) 1904: Pavilhão Bouneville (Juliano Moreira); c) 1930: expansão das redes escolares, quando surgem as primeiras classes especiais nas escolas públicas; d) 1938: Clínica de Orientação Infantil Serviço 
Médico Escolar do Instituto Higiene Mental; e) 1854: Asilos Meninos desvalidos (para formação profissional) (Lobo, 2003).

A história da criação dessas instituições possibilita que se visualize a representação da infância, adolescência e juventude pobres que vigorou no Brasil. A partir do século XVIII, predominava o "sentimento de pena" e o reconhecimento da necessidade de se oferecer abrigo, proteção e educação através de instituições caritativas. No século XIX, o Estado usou como medida ações disciplinares, nas quais crianças e adolescentes eram julgadas e enviadas às casas de detenção para serem "recuperadas". No século XX, eram vistos como "menores infratores" que precisavam de reclusão e de reeducação. Só no final do século XX, essa representação mudou em consequência de um intenso movimento de democratização do país, no bojo do qual toma forma a luta e a consolidação da doutrina jurídica da criança como sujeito de direito. Na trajetória de lutas e de mobilizações percorridas pelos movimentos sociais, especialmente a Frente Nacional de Defesa dos direitos das Crianças e Adolescentes, a Pastoral do Menor da Conferência Nacional dos Bispos do Brasil (CNBB) e o Movimento Nacional de Meninos e Meninas de Rua (MNMMR), se destacam como as articulações realizadas, junto à sociedade civil, para imprimirem na Constituição de 1988, o Art. 227; esta, por sua vez, cria a Lei Complementar 8.069 de 1990, denominada o Estatuto da Criança e do Adolescente (ECA), o qual contém os dispositivos para garantia dos Direitos. (Estatuto da Criança e do Adolescente, 2005).

As mudanças derivadas da redemocratização do país provocaram mudanças na atuação da Psicologia, especificamente na atuação junto à infância, adolescência e juventude: a necessidade de superar o paradigma da Psicologia pautado no modelo individual, clínico, do desenvolvimento natural, "etnocêntrica, que se pretende universal, missionária e civilizadora, e que nega qualquer singularidade ou outras formas de atribuir significados, e que vê o sujeito com uma visão patologizante" (Ropa \& Duarte, 1985, p. 201).

No que diz respeito à infância, adolescência e juventude, as mudanças emergiram em decorrência das conquistas no plano legal, ou seja, nos avanços no campo de seus direitos. Esses avanços foram concretizados na passagem da doutrina da situação irregular para a doutrina da proteção integral e da visão de crianças/adolescentes como sujeitos de direitos. A visibilidade de que são sujeitos em formação e de que as situações de riscos pessoais ou sociais podem significar danos ao desenvolvimento, fez com que, através de um processo de lutas travadas pelos movimentos sociais, o Estado brasileiro garantisse políticas públicas para promover e efetivar a garantia desses direitos. Nesse novo cenário que se configurou a partir da Constituição Federal de 1988 e do Estatuto da Criança e do Adolescente ECA (1990) surgiram demandas específicas para a Psicologia, enquanto um dos campos do saber com contribuições específicas.

Dentre essas contribuições, destacam-se as ações da Psicologia no âmbito da efetivação de direitos e a demanda por uma nova concepção de desenvolvimento humano. Nessa perspectiva do direito, vê-se a efetivação do exercício das diferenças, não como essência imutável e universal do homem, mas como meio de se construir, "garantir e afirmá-los enquanto diferentes modos de sensibilidade, diferentes modos de viver, existir, pensar, perceber, sentir; enfim, diferentes modos e jeitos de ser e estar neste mundo" (Coimbra, 2000, p. 142).

O desenvolvimento, numa perspectiva crítica, processase dentro de uma conexão dinâmica entre contexto e sujeito, o que permite refletir e se compreender o desenvolvimento humano articulado às relações sociais, e o sujeito como aquele que se constrói a partir do meio, da cultura. Compreende-se o desenvolvimento num processo dialético, no qual o ser humano se transforma inserido em uma relação complexa entre fatores internos e externos, que ocorre em condições materiais de vida (Vigotski, 1989).

Mas, tal assertiva colocava (e ainda coloca) para a Psicologia desafios, ou novos papéis, com os quais ela não estava familiarizada devido, entre outros aspectos, aos modelos teórico-metodológicos de que até então dispunha ou adotava, ao tipo de formação e intervenção que privilegiava, e à falta de compromisso social (Oliveira, 2011). Para ocupar esse lugar, a Psicologia demandava um modelo teórico e uma prática que dessem conta da nova realidade social-dinâmica, diversificada, constituída por sujeitos reais, ativos, historicamente situados numa sociedade excludente. A Psicologia carecia de uma perspectiva crítica.

Por perspectiva crítica na Psicologia, pensamos a perspectiva sócio-histórica que carrega consigo o compromisso com a crítica da visão hegemônica de homem na Psicologia, a crítica à naturalização do fenômeno psicológico como coisa em si, abstrata e universal, e que reside tão somente no indivíduo de forma a responsabilizá-lo por seu próprio desenvolvimento. Feita a crítica, essa perspectiva concebe o homem como ativo, social e histórico, constituído e constituinte, portanto, das práticas sociais. Crítica implica que a realidade seja tomada na sua totalidade, complexidade e, de modo dialético, a contemplar os movimentos e contradições "voltados ao investimento em ações, processos e relações que se contraponham às diferentes formas de injustiça e desigualdade social e, portanto, às suas causas político-econômicas concretas" (Delari Júnior, 2004, p. 03).

Nesse sentido, significa formar o profissional e atuar numa perspectiva do compromisso social; um trabalho que alie a "consciência crítica e atenção permanente e comprometida com as urgências e necessidades da população" (Bock, Ferreira, Gonçalves, \& Furtado, 2007, p.47). Compromisso social, aqui, é pensado como aquele compromisso com a mudança dessa realidade social, das desigualdades sociais. Nessa acepção, social está sendo definido como aquelas questões ou problemas que emergem no capitalismo a partir das relações capital-trabalho (Yamamoto, 2003), ou, mais especificamente, os processos de exclusão social que resultam, para crianças, adolescentes e jovens, em situações de riscos e vulnerabilidade.

Nesse sentido, a atuação do psicólogo, de um modo geral e, especificamente, na área da infância e juventude, precisa se dar no sentido de promover a articulação do objetivo e subjetivo, interno e externo, individual e social. Pois, não há linearidade no desenvolvimento, mas há processos de adaptação, nos quais os impedimentos que a criança encontra são superados. Essa superação advém da articulação dos fatores internos e externos. $\mathrm{O}$ interno representado pelas mudanças orgânicas e o externo 
representado pelos aspectos históricos. A realidade social é a verdadeira fonte de desenvolvimento (Vigotski, 1996, p. 264). O choque do comportamento da criança com as formas culturais ou sociais de comportamento é que fazem com que a criança se desenvolva. Nesse sentido, a diversidade, nas condições sociais, ativa diferentes processos de desenvolvimento (Palangana, 1994).

O mundo subjetivo é constituído pela interação das condições sociais e pela elaboração interna desse meio (como é vivido), que evidencia também o desenvolvimento do eu, configurado pela interação das diversas formas de experiências que constituem o ser humano. Assim, o meio não o constitui diretamente, mas esse processo ocorre de forma mediada, assumindo as peculiaridades da inter-relação entre diversas experiências (Vigotski, 1933-1934/ 2006).

\section{A experiência na formação de um pensamento crítico e a atuação do psicólogo na área da infância, ado- lescência e juventude}

É nesse novo contexto que tem se dado a experiência aqui relatada, desenvolvida em João Pessoa por um grupo constituído de alguns professores e estudantes de Psicologia da Universidade Federal da Paraíba, através das práticas de pesquisa, formação e intervenção junto a crianças e adolescentes, em situação de risco pessoal e social. São experiências de formação através do ensino (na graduação e na pós-graduação), da pesquisa, da extensão e do estágio (embora ensino seja situado com esse destaque) que, além da própria formação, visam contribuir para enfrentar a desigualdade social, principalmente nas temáticas que envolvem a violação dos direitos de crianças, adolescentes e jovens, especialmente do trabalho infantil, contextos de violência (nas situações de rua, na família, na escola, e na sociedade) e das políticas públicas de Assistência Social e de formação de jovens para o trabalho.

Nos dez anos que essa experiência de formação de profissionais de Psicologia numa perspectiva crítica tem se desenvolvido, contemplou-se uma série de ações visando a transformação da realidade de crianças e adolescentes em contextos de violência (física, psicológica, sexual e estrutural) e a formação de profissionais de Psicologia. Compreende-se que, como psicólogos, no espaço da academia, se ocupa um lugar importante para se fazer frente às desigualdades sociais, tendo a criança e o adolescente como focos principais dessa atuação, atuação essa que perpassa o tripé da academia (ensino, pesquisa e extensão). Compreende-se que esse tripé possibilita uma atuação, em via de mão dupla, de modo dialético. Ora o conhecimento produz intervenção, ora a intervenção gera produção de conhecimento, de modo que se pode conhecer a realidade para transformá-la e formar futuros profissionais que atuem de modo crítico e comprometido.

Nesse processo, entre 2001 e 2003, o foco das ações foi a formação de profissionais agentes de direitos humanos para atuarem no combate ao trabalho infantil. Essa formação e o contato com esses agentes geraram várias demandas de pesquisa, intervenção, articulação e assessoria, com crianças, adolescentes, jovens, famílias e instituições. Em 2004, o foco foi a intervenção com famílias através de um balcão de direitos.
Em 2005, deu-se continuidade à formação de profissionais agentes de direitos humanos. Entre 2003 e 2006, realizou-se uma pesquisa em parceria com instituições públicas governamentais de fiscalização, de justiça e internacionais, que possibilitaram o Mapeamento do Trabalho Infantil no Estado da Paraíba e se produziram relatórios técnicos sobre as piores formas de trabalho infantil em vários estados do Brasil, com a parceria da Organização Internacional do Trabalho (OIT). Em 2008 e 2009, fizeram-se pesquisas sobre a violência sexual nos documentos do Ministério Público, Juizado da Infância e Juventude e dos Conselhos Tutelares. O conhecimento produzido nas pesquisas gerou a demanda de que se avaliassem algumas políticas públicas, ou, mais especificamente, programas voltados para garantia de direitos de crianças e adolescentes. Entre eles, o Programa de Ações Integradas e Referenciais de Enfrentamento à Violência Sexual Infanto-Juvenil no Território Brasileiro (PAIR), o que se deu entre 2007 e 2008, e o Programa de Erradicação do Trabalho Infantil (PETI), entre 2009 e 2011, em vários municípios do estado.

Ao mesmo tempo em que essas pesquisas ou avaliação de políticas foram acontecendo, o resultado delas, desde 2008, são utilizados nas atividades de intervenção, através da extensão junto a crianças e adolescentes atendidos nas atividades socioeducativas do Programa de Erradicação do Trabalho Infantil (PETI) em João Pessoa. Esse trabalho de intervenção tem possibilitado, além do atendimento das crianças e de suas famílias, o trabalho com educadores sociais, professores da rede pública de educação, com a Rede do Sistema de Garantia de Direitos e formação dos profissionais de Psicologia, tanto em nível de graduação como de pós-graduação.

O conhecimento teórico produzido no conjunto das atividades de pesquisa, extensão e formação tem possibilitado compreender vários aspectos dessa realidade social da infância e juventude, dentre as quais se destacam:

O trabalho infantil caracteriza-se por contribuir na reprodução intergeracional da pobreza, por uma dimensão étnica (os trabalhadores precoces são predominantemente negros ou afrodescendentes) e, a depender da atividade, é permeado por questões de gênero. Além disso, o trabalho infantil tem implicações psicossociais no desenvolvimento (escolaridade, saúde física e psíquica, adultização precoce, negação da cidadania e falta de capital cultural para inserções profissionais na vida adulta).

A violência sexual tem como causas fatores culturais e socioeconômicos (pobreza, desigualdades sociais, a existência de rede de relações sociais que oportunizam a exploração, o contexto social de vulnerabilização, exclusão social, impunidade dos exploradores, violência familiar). Caracteriza-se por dimensões de gênero; repetição geracional; indeterminação de papéis destinados à família, à criança e ao adolescente; dificuldades em estabelecer nítidas fronteiras intergeracionais; violação dos direitos humanos universais e dos direitos peculiares a crianças e adolescentes. Por fim, os danos biopsicossociais gerados pelas situações de violência sexual referem-se à gravidez precoce, mortalidade materna, destacando-se lesões físicas gerais, lesões genitais, lesões anais; gestação e aborto; doenças sexualmente transmissíveis (DSTs), disfunções sexuais, 
sentimento de autodesvalorização e perda de dignidade humana, depressão, confusão de identidade e automutilação, drogadição, distúrbios na sexualidade e na alimentação, ideação e tentativas de suicídio, envolvimento com atos infracionais e problemas como desistência, reprovação e evasão escolar.

A formação de jovens para o trabalho, viabilizado pelas políticas públicas, constitui-se em formas de controle, disciplinamento, políticas de transferência de renda, formação técnica para atender demandas do capital. Esses aspectos foram identificados por Macêdo (2006), sobre o Programa da Aprendizagem do Serviço Nacional de Aprendizagem Comercial (SENAC); por Santos (2006), sobre o Programa Jovem Aprendiz do Serviço Nacional de Aprendizagem Industrial (SENAI); e Pessoa (2009), sobre a Formação e Expectativa dos jovens aprendizes no Centro de Integração Empresa Escola (CIEE). Tais políticas reproduzem o sentido do jovem como aquele necessitado, irresponsável, e que precisa aprender a se comportar nos moldes da empresa. Como as empresas não possuem uma política empresarial sistemática de acompanhamento e formação dos jovens que recebem, fazem-no porque são obrigadas por Lei (Máximo, 2012). A formação que teoricamente visa à inserção no mercado de trabalho também não é efetiva, pois as funções desempenhadas pelos jovens, em grande parte, não estão relacionadas ao período como aprendizes, destacando-se por seu caráter temporário e instável.

As políticas públicas voltadas para infância e juventude são ineficazes, ineficientes, e não efetivam as garantias de direitos. São desarticuladas, caracterizando-se como formas de configurar infâncias e juventudes, no caso em apreciação neste artigo, infância e juventudes das classes baixas. Configuram-se, assim, em formas de subjetivação que se caracterizam pela exclusão e assujeitamento. Cite-se, a título de exemplo, a pesquisa realizada por Silva, Alberto, Máximo e Nunes (2011). As autoras observaram que, para os gestores do Programa de Aprendizagem entrevistados, o benefício do Programa é pela utilização da mão de obra do aprendiz; refletem, contudo, uma visão estereotipada de juventude como aquele que sabe menos ou que não tem as mesmas capacidades que os demais trabalhadores, restando a eles as atividades mais automáticas, "simplórias", o que contradiz o objetivo do Programa de desenvolvimento dos jovens.

O conhecimento e a intervenção nessa realidade possibilitaram compreender-se o desenvolvimento da infância e juventude que se processa diante dessas condições sociais objetivas, das relações sociais e do sujeito que se constrói a partir do trabalho precoce, da violência, usuários das políticas públicas (Vigotski, 1989). Sujeitos em processo de desenvolvimento (Estatuto da Criança e do Adolescente, 2005), sem garantias de direitos, sem acesso à cidadania, vitimizados e vulneráveis, mas que, paradoxalmente, agem, protagonizam, se rebelam, criam, reivindicam, transformam o contexto, ativam diferentes processos de desenvolvimento (Palangana, 1994) . Conhecer essa realidade possibilitou fazer-se uso de um pensamento crítico de tomá-la em sua totalidade e contemplando suas contradições (Delari Júnior, 2004). Para se atuar com essa infância e juventude, é necessária a mediação dos aspectos objetivos e subjetivos, cultural e psíquico. Pensamento crítico que compreende a infância e a juventude como historicamente construídas, decorrentes das relações com a sociedade e com os elementos que a constituem. Logo, o desenvolvimento não é linear, universal e natural, mas contextualizado. Contexto entendido como relação entre tempo, lugar e sujeito.

Os riscos e a vulnerabilidade que vitimizam essa forma de infância e juventude não são tomadas nessa experiência de formação como engessamento, como patologizante (Ropa $\&$ Duarte, 1985), que qualifica como sujeito incapaz, sujeito problema, sujeito perigoso, mas olha os aspectos objetivos como materialização de uma subjetividade que é dinâmica, que constitui diferentes modos de sentir, existir e agir (Coimbra, 2000). Citem-se, a título de exemplo, passagens dessa experiência quando se percebeu, ao abordar a questão dos direitos, que vários sujeitos que vivenciam essa forma de infância e de juventude não conseguem perceber os direitos expressos no ECA como algo que lhes diga respeito e dos quais deveriam ser sujeitos. Mas, no processo das intervenções via extensão, o ato de garantir voz ativa a todos eles fez despertar em alguns a percepção de que podem fazer diferente, desde que sejam explicitadas as ferramentas necessárias para isso, e que os psicólogos (e estudantes em formação) tomem aí um papel de facilitadores dessa mudança. Emergem daí sujeitos cheios de imaginação e desejos que, mesmo quando suas brutais realidades não as deixavam desfrutar da infância e da juventude, nem gozar de seus direitos enquanto tais, conseguiam criar perspectivas de futuro pautadas pela importância que atribuem ao estudo e à escola.

O significado dessa formação, numa perspectiva crítica, tem sido o de formar para atuar com crianças e jovens em defesa dos seus direitos e, ao mesmo tempo, produzir conhecimento que possibilite avançar teoricamente e seja útil para a realidade, para a práxis, o que significa fazer uso de um referencial crítico que possibilite ao estudante e futuro profissional acesso ao conhecimento que lhe permita experimentar vivências, nas quais a atuação viabilize garantia de direitos e processos de empoderamento, autonomia e protagonismo. Vivência, numa perspectiva crítica, deve ser compreendida como a relação interior do ser humano com um momento da realidade. A vivência, enquanto unidade dinâmica da consciência, comporta as mesmas características desta, ou seja, a inter-relação indivisível entre aspectos cognitivos e afetivos (Vigotski, 19331934/ 2006).

Mas, no processo de formação de psicólogos críticos, há uma série de dificuldades com as quais se defrontam; uma dessas dificuldades reside no modelo filosófico e pedagógico dos cursos de formação em Psicologia que consistem, na maioria das vezes, numa formação acadêmica que não dá subsídios para uma atuação comprometida, pois se restringe a um modelo clínico tradicional, numa perspectiva individualizante e descontextualizada, insuficiente de "leituras que, ao falarem do mundo psíquico, falem do mundo social e, ao pensarem em transformações, psíquicas, exijam um projeto social" (Bock, 2009 , p. 23). Outra dificuldade reside no próprio estudante que, muitas vezes, se apresenta para a formação defendendo uma concepção apolítica na atuação do profissional de Psicologia.

Atuar na realidade de crianças e jovens pobres significa refletir sobre aspectos estruturais que, ao mesmo tempo em que 
geram situações de desigualdade, precisam favorecer condições que promovam a construção do pensar crítico e de suas ações em busca da efetivação dos seus direitos e deveres. Ao mesmo tempo, produzir conhecimento que seja útil para a realidade, em uma perspectiva teórica dialética que contemple teoria e prática, processo e não produto, que compreenda a realidade a partir das nuances históricas, culturais, econômicas, políticas e psicológicas (Vigotski, 1996).

A práxis nessa experiência tem como ferramenta a escuta do sujeito implicado. A escuta ressoa no psicólogo que contribui no processo de delineamento da demanda. Essa demanda emana da criança, do jovem, das mães, da escola, do Sistema de Garantia de Direitos, das instituições, das Redes etc. Delineada a demanda, demandante e profissional de Psicologia, numa ação conjunta, atuam juntos para identificar as possibilidades e planejar as ações. O que significa um profissional com formação teórica e metodológica, mas também comprometido socialmente (Bock et al, 2007).

A atuação do estudante de graduação, de pós-graduação em formação, e do profissional é o do compromisso social, implicado. Efetiva-se, a partir das intervenções, a possibilidade de atuar no cotidiano das desigualdades e violências, promovendo e favorecendo o desenvolvimento e a autonomia dos sujeitos (Conselho Federal de Psicologia, 2009). Esse compromisso, referenciado teoricamente na Psicologia Sóciohistórica, tem, para o psicólogo, o papel de mediação. Mediação significa a participação do psicólogo nas situações sociais com que pretende agir e transformar. Implica transformação de si, diálogo com outros saberes, compreensão do conjunto de fatores que compõem a realidade social e a existência dos sujeitos sociais (objetiva e subjetiva).

Além da construção de uma perspectiva de formação crítica de profissionais de Psicologia, essa práxis tem dado outros frutos: Ações em Rede e efetivação da garantia de direitos (família e criança); profissionais formados e ocupando espaços de elaboração de políticas, gestão, execução e controle social; protagonismo das crianças e adolescentes que reivindicam garantia de direitos; intervenções junto aos gestores de política no sentido de proposição de ações; assessoria na Elaboração dos Planos Municipais de Combate ao Trabalho Infantil e de Enfrentamento da Violência Sexual contra Crianças e Adolescentes.

Esses frutos são coerentes com a perspectiva crítica em vários aspectos: o profissional de Psicologia, além de aprender a ser profissional, deve gerar, nessa aprendizagem, uma intervenção que aja transformando a realidade. No espaço no qual intervêm, as relações sociais que estabelecem se dão no sentido de um sujeito implicado, comprometido, e cuja formação é também uma ferramenta de mediação entre os indivíduos com os quais interage e as instituições sociais, a sociedade ou o Estado. Essa mediação deve consistir numa mediação de conflito, no acesso e garantia de um direito ou no processo de empoderamento do cidadão, seja esse cidadão uma criança, um adolescente, um jovem ou um adulto. Do mesmo modo, o estudante de pós-graduação e o estudante de graduação que aprendem através da pesquisa geram um conhecimento, e suas produções são devolvidas gerando uma intervenção. Essa intervenção é variável, a depender da realidade estudada, mas cujo conhecimento, no ato de produzirse e no processo devolutivo, gera uma ação. Cite-se, a título de exemplo, a devolução dos dados de uma tese com jovens e gerentes acerca do Programa de Aprendizagem. Uma política do governo federal de formação para o trabalho, para um conjunto de instituições - participantes - contribuiu na criação de um Fórum de Aprendizagem. Ou seja, um Fórum composto por instituições governamentais e não governamentais cuja proposta de atuação é a defesa do trabalhador jovem.

\section{Considerações finais}

A construção de um pensamento crítico, na formação de profissionais de Psicologia que atuem na área da infância, adolescência e juventude, requer a utilização de um modelo teórico pautado no desenvolvimento de uma cultura de direitos humanos. Entende-se que nosso papel é o de mediador e de sujeito implicado. Para tal, trabalha-se com a concepção de infância e adolescência como construções sociais, históricas, marcadas por longo processo de exclusão social. Atua-se, então, de modo comprometido com o processo de efetivação da cidadania de crianças, adolescentes, entendendo-se que a cidadania parte de um processo de luta e de reivindicação dos direitos, por meio de ações coletivas, da conscientização e do empoderamento de suas vidas. Busca-se efetivar uma práxis na direção do resgate e efetivação da cidadania de crianças e adolescentes, do direito de vivenciar a infância e adolescência. Mediam-se saberes e práticas, dimensões objetivas e subjetivas, exercendo-se um papel social ativo e crítico que contribua na transformação dessa realidade.

\section{Referências}

Bock, A. M. B., Ferreira, M. R., Gonçalves, M. G. M., \& Furtado, O. (2007). Sílvia Lane e o projeto do "Compromisso Social da Psicologia". Psicol. Soc., 19(2), 46-56. Recuperado de http://www.scielo.br/pdf/psoc/v19nspe2/a1819ns2.pdf

Bock, A. M. B, Furtado, O, \& Teixeira, M. L. T. (2001). Psicologias: uma introdução ao estudo da psicologia (13 ${ }^{\underline{a}}$ ed.). São Paulo: Saraiva.

Bock, A. M. B. (2009). Psicologia e sua ideologia: 40 anos de compromisso com as elites. In A. M. B. Bock (Org.), Psicologia e o compromisso social (pp. 15-28). São Paulo: Cortez.

Coimbra, C. M. B. (2000). Psicologia, direitos humanos e neoliberalismo. Revista Psicologia Politica, 1 (1), 139-148. Recuperado de: http://www.fafich.ufmg. $\mathrm{br} / \sim \mathrm{psicopol} / \mathrm{pdfv} 1 \mathrm{r} 1 /$ Cecilia.pdf

Conselho Federal de Psicologia (2009). Serviço de proteção social a crianças e adolescentes vítimas de violência, abuso e exploração sexual e suas famílias: referências para a atuação do psicólogo ( $1^{\underline{a}}$ ed.). Brasília: Autor.

Delari Junior, A. (2004). Cinco critérios para a formação do psicólogo: da coerência ética à competência técnica. In VIII JOP - Jornada Internacional de Psicologia. Umuarama, Paraná.

Estatuto da Criança e do Adolescente (2005). Brasília: Senado Federal. Subsecretaria de Edições Técnicas.

Lobo, L. F. (2003). Higienismo e normalização da infância no Brasil. In A. M. Jacó-Vilela, A. C. Cerezzo \& H. B. C. Rodrigues (Orgs.), Clio-Psyché Paradigmas: historiografia, psicologia, subjetividades (pp.291-320). Rio de Janeiro: FAPERJ.

Macêdo, O. J. V. (2006). O sentido da formação para o trabalho e as expectativas em relação ao futuro por parte dos adolescentes aprendizes. (Dissertação de Mestrado). Universidade Federal da Paraíba, João Pessoa. 
Máximo, T. A. C. O. (2012). Significado da formação e inserção profissional para gestores e aprendizes egressos do programa jovem aprendiz. (Tese de Doutorado). Universidade Federal da Paraíba, João Pessoa.

Oliveira, M. V. (2011). Mesa: a ação clínica e os espaços institucionais das políticas públicas: desafios éticos e técnicos. In Conselho Federal de Psicologia (Org.), $V$ Seminário Nacional Psicologia e Políticas Públicas - Subjetividade, Cidadania e Políticas Públicas (pp 87-106). Brasília: CFP.

Palangana, I. C. (1994). Desenvolvimento \& aprendizagem em Piaget e Vygotsky: (a relevância do social). São Paulo: Plexus.

Pessoa, M. C. B. (2009). Programa da aprendizagem no contexto do CIEE: finalidade da formação e expectativas dos aprendizes. (Monografia não publicada). Universidade Federal da Paraíba, João Pessoa.

Ropa, D., \& Duarte L. F. D. (1985). Considerações teóricas sobre a questão do atendimento psicológico às classes trabalhadoras. In S. Figueira (Org.), Cultura da psicanálise (pp. 178-201). São Paulo: Brasiliense.

Santos, D. P. (2006). Relatório de estágio em psicologia social na delegacia regional do trabalho. Manuscrito não publicado, Universidade Federal da Paraíba, João Pessoa.

Silva, R. M. P., Alberto, M. F. P., Máximo, T. A. C. O., \& Nunes, T. S. (2011). Programa adolescente aprendiz: mecanismo efetivo de inserção dos jovens no mercado de trabalho? In M. F. P. Alberto, J.A. Lima \& D. P. Santos (Orgs.), Infância, adolescência e juventude: pesquisa, intervenção e políticas públicas. João Pessoa: Editora Universitária.

Vigotski, L. S. (1989). Pensamento e linguagem. (2 ${ }^{\underline{a}}$. ed.). São Paulo: Martins Fontes.

Vigotski, L. S. (1996). Teoria e método em psicologia. (C. Berliner, Trad.). São Paulo: Martins Fontes.

Vigotski, L. S. (2006). La crisis de los siete años. Obras Escogidas. Tomo IV (pp. 377-386). Madrid: Visor. (Obra original publicada em 1933-1934)

Yamamoto, O. H. (2003). Questão social e políticas públicas: revendo o compromisso da Psicologia. In A. M. M. Bock (Org.), Psicologia e o compromisso social (pp. 37-54). São Paulo: Cortez.

Maria Fatima Pereira Alberto, doutora em Sociologia pela Universidade Federal de Pernambuco, é professora associada da Universidade Federal da Paraíba. Endereço para correspondência: Universidade Federal da Paraíba, Centro de Ciências Humanas Letras e Artes - Campus I, Departamento de Psicologia, Cidade Universitária - Campus I, Castelo Branco. CEP 58000-000. Joao Pessoa, PB. E-mail: jfalberto@uol.com.br 